EPJ Web of Conferences 110,01019 (2016)

DOI: $10.1051 /$ epjconf/201611001019

(C) Owned by the authors, published by EDP Sciences, 2016

\title{
NUMERICAL RESEARCH OF STEAM AND GAS PLANT EFFICIENCY OF TRIPLE CYCLE FOR EXTREME NORTH REGIONS
}

\author{
Galashov Nikolay ${ }^{1,}$ a, Tsibulskii Svjatoslav ${ }^{1}$, Matveev Aleksandr ${ }^{1}$, Masjuk Vladimir ${ }^{1}$ \\ ${ }^{1}$ National Research Tomsk Polytechnic University, 634050 Tomsk, Russia
}

\begin{abstract}
The present work shows that temperature decrease of heat rejection in a cycle is necessary for energy efficiency of steam turbine plants. Minimum temperature of heat rejection at steam turbine plant work on water steam is $15^{\circ} \mathrm{C}$. Steam turbine plant of triple cycle where lower cycle of steam turbine plant is organic Rankine cycle on low-boiling substance with heat rejection in air condenser, which safely allows rejecting heat at condensation temperatures below $0^{\circ} \mathrm{C}$, has been offered. Mathematical model of steam and gas plant of triple cycle, which allows conducting complex researches with change of working body appearance and parameters defining thermodynamic efficiency of cycles, has been developed. On the basis of the model a program of parameters and index cycles design of steam and gas plants has been developed in a package of electron tables Excel. Numerical studies of models showed that energy efficiency of steam turbine plants of triple cycle strongly depend on low-boiling substance type in a lower cycle. Energy efficiency of steam and gas plants net $60 \%$ higher can be received for steam and gas plants on the basis of gas turbine plant NK-36ST on pentane and its condensation temperature below $0^{\circ} \mathrm{C}$. It was stated that energy efficiency of steam and gas plants net linearly depends on condensation temperature of lowboiling substance type and temperature of gases leaving reco very boiler. Energy efficiency increases by $1 \%$ at $10 \%$ decrease of condensation temperature of pentane, and it increases by $0.88 \%$ at $15^{\circ} \mathrm{C}$ temperature decrease of gases leaving recovery boiler.
\end{abstract}

\section{Introduction}

According to the energy strategy in Russia till 2030 generating power working on gas should be steam and gas plants. The main gas deposits in Russia are in Extreme North regions in peninsula Yamal, where average ambient air temperatures during five months are below $20^{\circ} \mathrm{C}$. Gas from deposits is transported along gas pipelines with the help of transfer stations on which gas transfer stations are installed on the basis of gas turbine engines. Cost of $1 \mathrm{~km}$ gas pipelines 'Sila Sibiri' into transfer stations with the cost accounting is about $5 \mathrm{mln}$. USD, besides a large amount of gas on transfer stations is burnt for gas transportation and energy generation for own requirements. A big part of gas after its transportation is burnt at thermal power plant for electrical energy generation. One of the ways of energy and resources conservation is generation and transportation of electric power from gas deposits. $1 \mathrm{~km}$ of electricity transmission line with voltage $750 \mathrm{~kW}$ costs $5 \mathrm{mln}$. RUR. It is necessary to build a thermal power plant with steam and gas plant at gas deposit for electrical energy generation, and it is also possible to modernize steam and gas turbines for using their heat from leaving gases in

${ }^{\text {a } C o r r e s p o n d i n g ~ a u t h o r: ~ g a l @ t p u . r u ~}$ 
steam turbine cycle. Low air temperatures can be used for energy efficiency increase in electrical energy generation plants with air condensers for heat rejection.

Nowadays the most effective electrical energy generation plants are steam and gas plants of utilization type [1]. Utilization steam and gas plants allow solving a range of economical and ecological problems in energetics by means of low capital expenses, high energy efficiency, small emissions release, small water consumption for technological process [2]. Steam and gas plants are a combination of two energetic plants: gas turbine and steam turbine ones. Gas turbine plant is important for steam turbine plant of utilization type $-2 / 3$ of power is generated on it and energy efficiency strongly depends on gases temperature before its turbine. Gas turbine plant can be used not only for electrical energy generation but also for drive mechanism of in-house needs [3], which allows increasing electrical energy rejection from steam and gas plant.

Multiwatt electrical energy plants of new generation at gas temperatures before turbine $1500^{\circ} \mathrm{C}$ created in the last years have energy efficiency about $40 \%$. Gas turbine plants of average power increased energy efficiency up to $36 \%$.

\section{Steam and gas plant scheme of triple cycle}

Energy efficiency of steam turbine plants depends on steam temperature before steam turbine and on temperature of heat rejection in condenser. Steam temperature before steam turbine is defined with temperature of gases leaving gas turbine plant and can reach $600^{\circ} \mathrm{C}$. Temperature increase for energy efficiency increase is connected with expensive gas turbine plant and steam turbine plant and decrease of their safety and maneuverability. Temperature of heat rejection in condenser at steam turbine plant working on water steam is limited with temperature of water freezing $-0^{\circ} \mathrm{C}$, and because of economical conditions it is usually not less than $15^{\circ} \mathrm{C}$. In north regions where air temperature is below $0^{\circ} \mathrm{C}$ for a long time, temperature of heat rejection in a cycle can be reduced with the help of air condensers instead of water ones, and using substances not freezing at low temperatures as working bodies and which are used in organic Rankine cycle. But these substances are destroyed at temperatures higher than $400^{\circ} \mathrm{C}$. That is why steam and gas plant was offered on the basis of three cycles: upper - gas turbine Brighton cycle, middle - steam turbine Rankine cycle and lower - organic Rankine cycle. Use of low-boiling substances in organic Rankine cycle also allows increasing dimensions and cost of turbine significantly and increase safety work of air condenser.

The present work [4] shows that for steam and gas plant of triple cycle with modern gas turbine plant and binary cycle of steam turbine plant energy efficiency net weight can be received up to $63 \%$. To receive high energy efficiency issues on optimal scheme of steam and gas plant and working bodies for steam turbine plant cycles choice are up-to-date.

Optimal scheme for steam and gas plant without interval overheating in the upper cycle of steam turbine plant is shown in fig. 1 . 


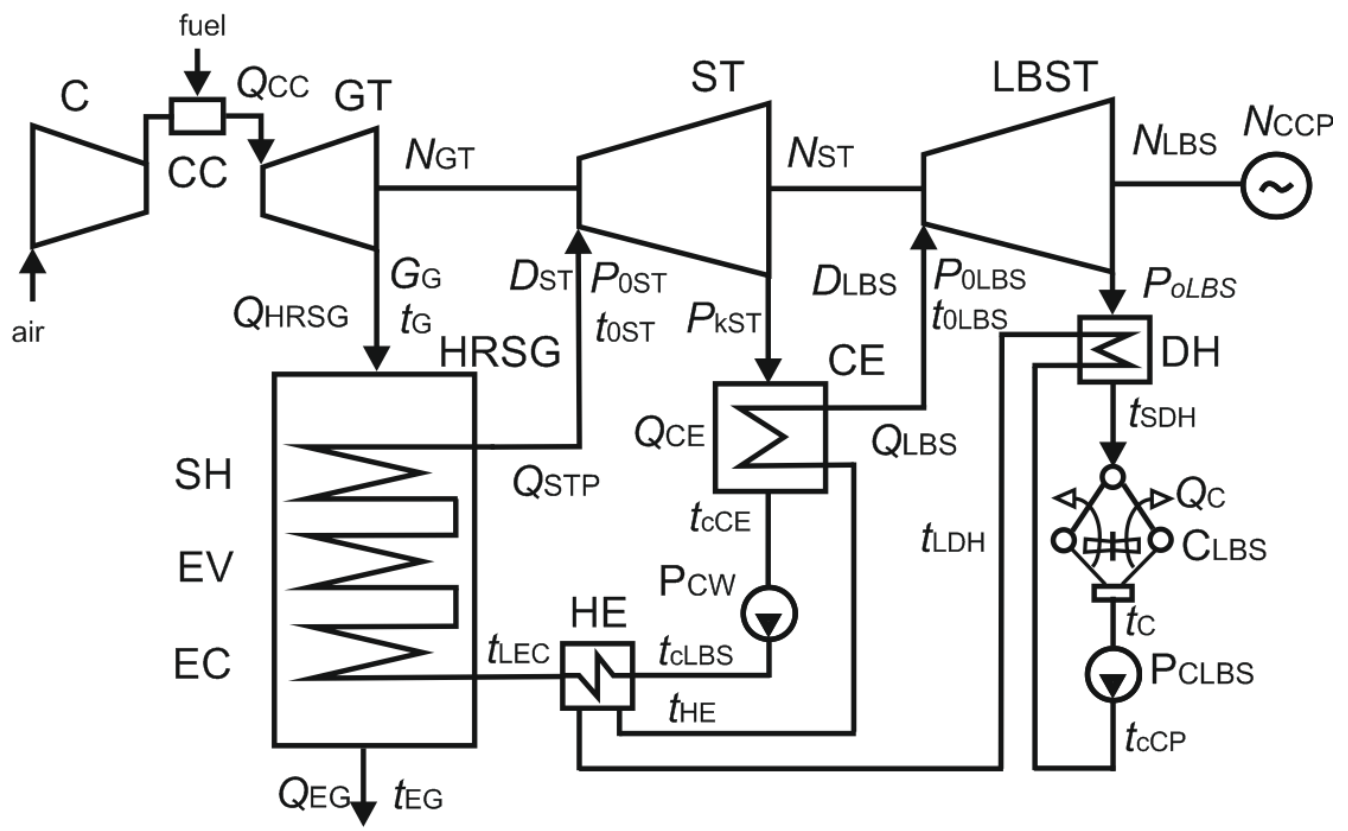

Figure 1. Steam and gas plant scheme of triple cycle.

Equipment and parameters in fig. 1 have the following designations: $\mathrm{C}-$ compressor; $\mathrm{CC}-$ combustion chamber; GT, ST и LBST - turbines: gas, steam and LBS; HRSG - heat-recovery steam boiler; $\mathrm{CE}$ - condenser-evaporator; $\mathrm{C}_{\mathrm{LBS}}$ - air condenser LBS; DH - desuperheater; HE - heat exchanger; $\mathrm{P}_{\mathrm{CW}} \mathrm{P}_{\mathrm{CLBS}}$ - pumps of steam water condenser transfer and LBS; $Q_{\mathrm{CC}}-$ heat power of gas turbine plant input into combustion chamber; $N_{\mathrm{GT}}, N_{\mathrm{ST}}, N_{\mathrm{LBS}}$ - received in GT, ST and LBST internal power; $Q_{\mathrm{HRSG}}$ - heat power from $\mathrm{T}_{\mathrm{g}}$ to HRSG; $Q_{\mathrm{EG}}$ - heat power rejected from HRSG into environment with leaving gases; $Q_{\mathrm{STP}}, Q_{\mathrm{LBS}}-$ steam turbine plant and LBS heat power input in cycles; $Q_{\mathrm{CE}}-$ heat power transferred from CE from condensing water steam to low-boiling substance; $Q_{\mathrm{C}}-$ heat power rejected in condenser LBS into environment; $G_{\mathrm{G}}$ - gases rate from gas turbine plant in HRSG; $t_{\mathrm{G}}, t_{\mathrm{EG}}-$ gas temperature on input and output HRSG; $D_{\mathrm{ST}}, D_{\mathrm{LBS}}-$ steam rate in cycles of steam turbine plant and LBS; $P_{0 \mathrm{ST}}, P_{0 \mathrm{LBS}}, t_{0 \mathrm{ST}}, t_{0 \mathrm{LBS}}-$ steam pressure and temperature before turbines $\mathrm{T}_{\mathrm{p}}$ and $\mathrm{T}_{\mathrm{HKB}} ; t_{\mathrm{c}}-$ condensation temperature in $\mathrm{C}_{\mathrm{LBS}} ; t_{\text {p.c. }}-$ steam temperature in LBS in the condensation output; $t_{\mathrm{cCE}}$ - condensation temperature in $\mathrm{CE}$; $t_{\mathrm{SDH}}, t_{\mathrm{cCE}}-$ condenser temperature for $\mathrm{P}_{\mathrm{CW}}$ and $\mathrm{P}_{\mathrm{CLBS}}$; $t_{\mathrm{cCP}}, t_{\mathrm{cLBSO}}$ - liquid temperature of LBS in the condensation output and HE; $t_{\mathrm{LEC}}-$ water temperature in the input into economizer HRSG.

\section{Research on steam and gas plants model}

Steam and gas plants mathematical model has been developed on the basis of gas turbine plant NK36ST which is widely used at gas transmission plants and has the following parameters for research in accordance with fig. $1: N_{\mathrm{GT}}=25 \mathrm{MBT} ; \eta_{\mathrm{gtp}}=36 \% ; G_{\mathrm{r}}=101.3 \mathrm{~kg} / \mathrm{s} ; t_{\mathrm{r}}=457^{\circ} \mathrm{C}$.

Mathematical model is a system of equations which characterize design: gases expansion processes in turbines; processes in pumps; material and energetic balances in heat exchange equipment. For the lower cycle on the basis of Russian and foreign works on working substances application in organic Rankine cycle analysis the following low-boiling substance types were developed: ammonia, ethanol, toluene, butane, pentane, and freons R236fa and R245fa. Mathematical model was realized by software program in a package of electron tables Excel. Design of thermodynamic and thermo physical air parameters, steam and gas plants leaving gases, water and low-boiling substance type are produced according to functions of the library "REFPROP" [5]. 
Results of numerical studies on models with condensation temperature change of low-boiling substance type and gases leaving recovery boiler are in fig. 2, 3. The following parameters were taken at steam turbine plant design: $P_{0 \mathrm{st} .}=16 \mathrm{MPa} ; t_{0 \mathrm{st} .}=440^{\circ} \mathrm{C} ; P_{\mathrm{C}}=0.2 \mathrm{MPa} ; t_{\mathrm{w.ec} .}=60^{\circ} \mathrm{C}$.

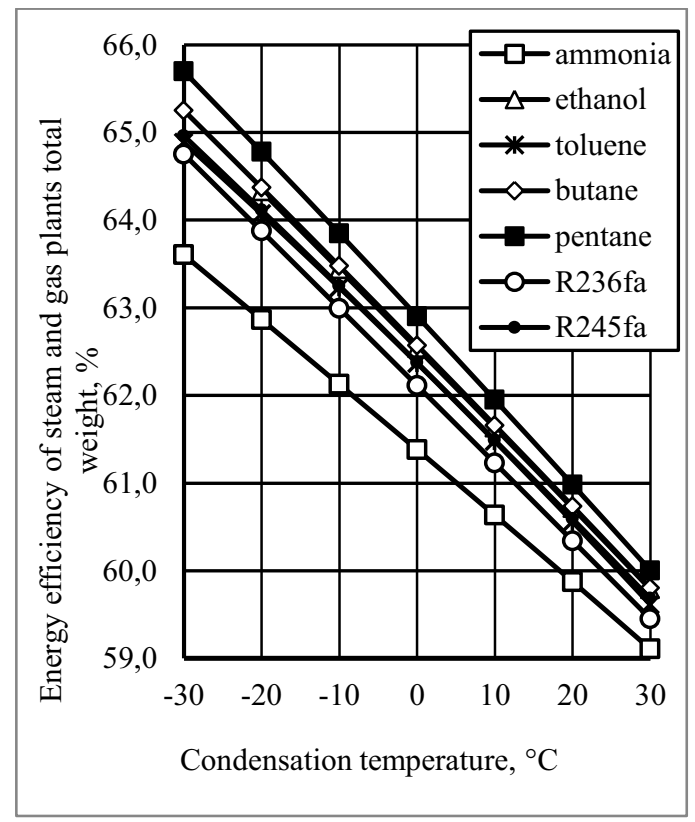

$a$

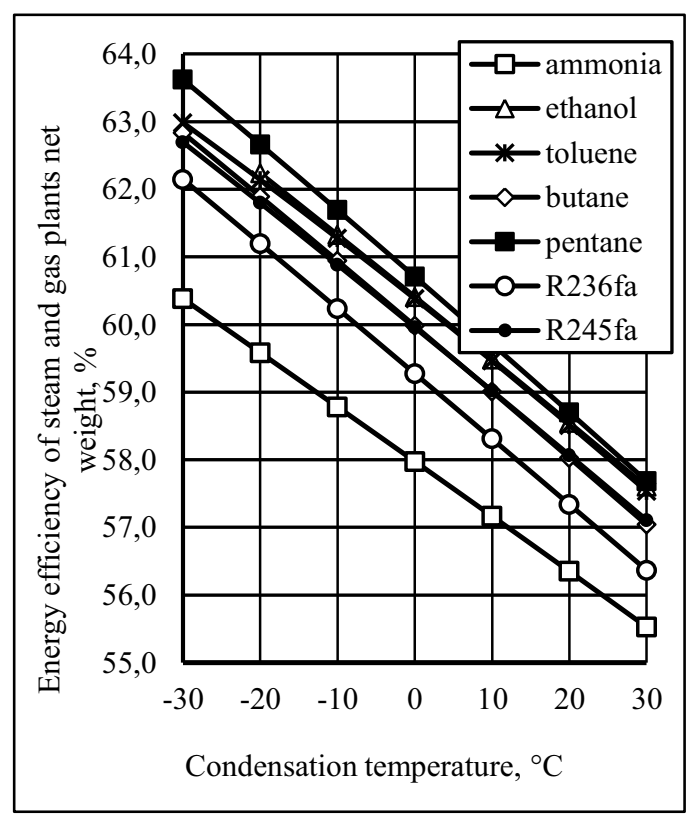

$b$

Figure 2. Energy efficiency of steam and gas plants dependence of total weight $(a)$ and net weight $(b)$ on condensation temperature of low-boiling substance type at temperature of gases leaving recovery boiler $75^{\circ} \mathrm{C}$.

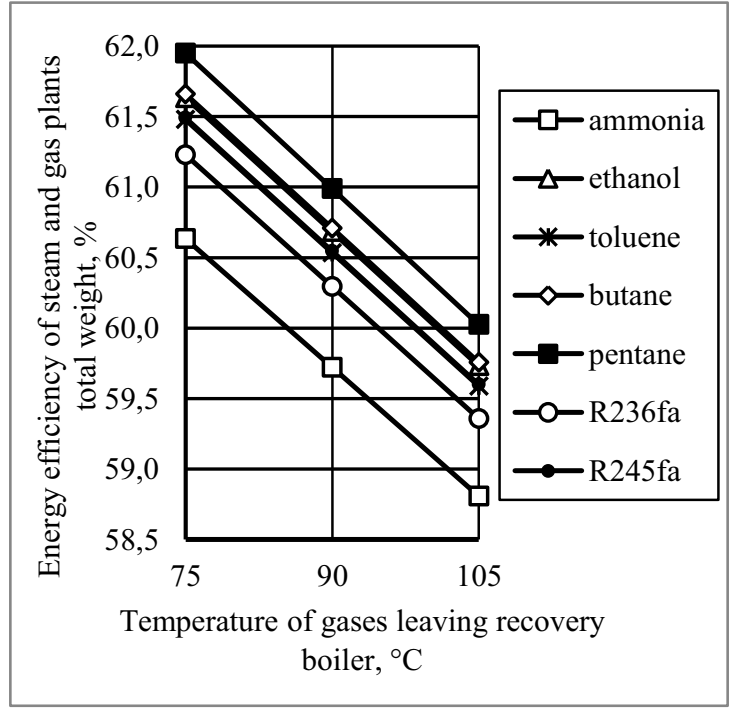

$a$

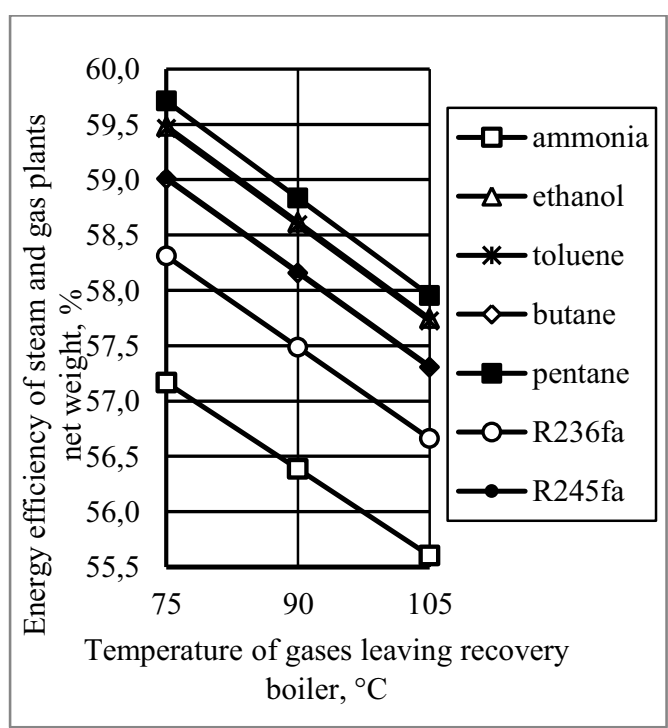

$b$

Figure 3. Energy efficiency of steam and gas plants dependence of total weight $(a)$ and net weight $(b)$ on temperature of gases leaving recovery boiler at condensation temperature $10^{\circ} \mathrm{C}$. 


\section{Research results analysis}

As we can see in fig. 2, 3 energy efficiency of steam and gas plants strongly depends on low-boiling substance type. The best substance among the substances taken into account is pentane, the second place is taken by ethanol and toluene, butane and freons R236fa and R245fa follow them. The last place is taken by ammonia which is connected with big losses from moisture in ammonia turbine and energy expenses on pumps. We can also notice almost linear dependence of energy efficiency of total weight and net weight on condensation temperature and temperature of gases leaving recovery boiler. Condensation temperature decrease by $10 \%$ for pentane increases energy efficiency of total weight by $0.95 \%$ and energy efficiency of net weight by $1.00 \%$, and decrease of temperature of gases leaving recovery boiler by $15^{\circ} \mathrm{C}$ increases energy efficiency of total weight by $0.96 \%$, and energy efficiency of net weight by $0.88 \%$.

\section{Conclusion}

The numerical studies showed:

- Energy efficiency of steam and gas plants of triple cycle depend on the low-boiling substance type in the lower cycle.

- Energy efficiency of steam and gas plants net $60 \%$ higher can be received for steam and gas plants on the basis of gas turbine plant NK-36ST on pentane and its condensation temperature below $0^{\circ} \mathrm{C}$.

- Energy efficiency of steam and gas plants net linearly depends on condensation temperature of low-boiling substance type and temperature of gases leaving recovery boiler. Energy efficiency increases by $1 \%$ at $10 \%$ decrease of condensation temperature of pentane, and it increases by $0.88 \%$ at $15^{\circ} \mathrm{C}$ temperature decrease of gases leaving recovery boiler.

The work has been done in framework of federal focused program implementation "Competitiveness Enhancement Program” of National Research Tomsk Polytechnic University.

\section{References}

1. R. Kehlhofer, F. Hannemann, F. Stirnimann, B. Rukes. Combined-Cycle Gas \& Steam Turbine Power Plants. Copyright (PennWell Corporation, 2009).

2. P. Viebahn, J. Nitsch, International journal of greenho use gas control, 1, (2007).

3. N. Galashov, Power Technology and Engineering. 47, 3 (2013).

4. Galashov N.N., S. Tsibulskii, Power Technology and Engineering. 48, 6 (2015).

5. E. Lemmon, M. Huber, M. McLinden, Reference fluid thermodynamic and transport propertiesREFPROP, standard reference database 23, version 8.0 (National Institute of Standard and Technology, 2007). 